\title{
NUEVOS ANTECEDENTES DEL MAPA DE ÚLTIMA ESPERANZA PRODUCIDO POR HERMANN EBERHARD, 1895
}

\author{
Introducción y Notas \\ Por Samuel García-Oteiza ${ }^{a}$
}

"Es especialmente absurdo intentar descalificar algunas imágenes bajo el argumento de que aparentemente han sido "manipuladas".

Todas las imágenes del mundo son el resultado de una manipulación, de un esfuerzo voluntario en el que interviene la mano del hombre (incluso cuando ésta sea un artefacto mecánico)"

George Didi-Huberman ${ }^{\mathrm{b}}$

I.

Esta entrega tiene como objetivo aportar nuevos antecedentes sobre el mapa geográfico de la comarca de Última Esperanza en Fuegopatagonia, producido por el marino-estanciero Hermann Eberhard (Fig. 1). El mapa se titula "Croquis (only). Last Hope Inlet and adjaccent country" y fue redescubierto el 2016 en el Archivo Nacional de Chile. Si bien el mapa bilingüe de Eberhard ${ }^{1}$ había sido publicado el 2010, erróneamente se adscribía a Punta Arenas ${ }^{2}$, incluso a Aysén ${ }^{3}$. El primer trabajo donde se comenta este mapa corresponde a Mateo Martinic (Martinic, 2017).

Recientemente se halló un documento escrito del cual el mapa formaba parte (Fig. 2). Gracias a su desclasificación, es posible contextualizar el mapa de Eberhard de mejor forma y entender el porqué un mapa producido por un vecino de la comarca de Última Esperanza llegó a la metrópoli de Santiago, emplazada a casi 3.000 kilómetros de distancia. Resulta extraño que no existan antecedentes sobre la producción de este mapa. Hasta donde se sabe, ni siquiera el mismo Eberhard hizo referencia alguna sobre él (Cf. Eberhard, 2018).

El mapa de Eberhard es copia única, fue confeccionado de manera manual y dibujado en base a lápices y acuarela. Fue dibujado en escala 1:200.000 y sus dimensiones físicas son $45.5 \times 54.5$ $\mathrm{cm}^{4}$. Contiene información, por aquel entonces, inédita

a Académico de la Escuela de Arquitectura, Departamento de Obras Civiles, Universidad Católica del Maule. Investigador asociado al Centro de Estudios del Hombre Austral, Instituto de la Patagonia, Universidad de Magallanes. $\$ samuelgarciaoteiza@gmail.com

b "Cómo abrir los ojos", en: Farocki, H. (2020). Desconfiar de las imágenes. Buenos Aires: Caja Negra. p. 13.

1 Contiene textos en inglés y castellano.

2 Rosenblitt, J., y Sanhueza, C. (Comp.) (2010). Cartografía Histórica de Chile 1778-1929. Santiago: DIBAM, p. 232

3 En el sitio web "Memoria Chilena" este mapa sigue inscrito en: "Exploradores y colonos de Aysen", http://www.memoriachilena. gob.cl/602/w3-article-620.html\#imagenes. Si bien en el 2017 nos acercamos al equipo de Memoria Chilena para comentar dicha imprecisión, nuestra aclaración no ha tenido acogida

4 Esta medida corresponde a las dimensiones de la hoja. 


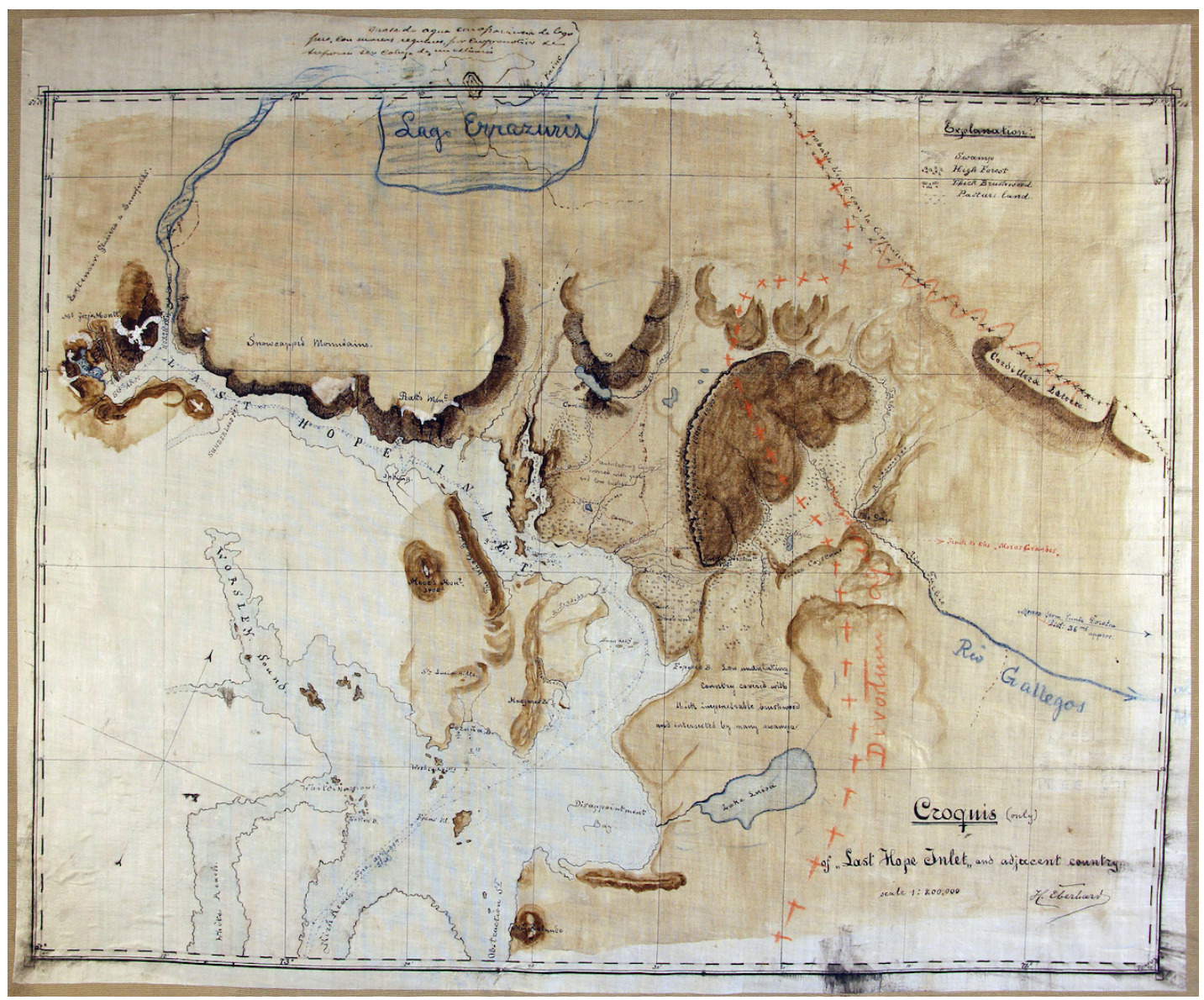

Fig. 1. Mapa producido por Hermann Eberhard titulado "Croquis (only). Last Hope Inlet and adjaccent country", dimensiones físicas $45.5 \times 54.5 \mathrm{~cm}$. (fotografía del autor, Mapoteca Archivo Nacional de Chile, $\mathrm{N}^{\circ} 981$ ).

de la comuna de Última Esperanza, principalmente geográfica ${ }^{5}$, derroteros ${ }^{6}$, ambiental $^{7}$, toponímica, caminera $^{8}$, antrópica, fronteriza ${ }^{9}$, entre otras. En este mapa aparece la primera referencia a la conocida "Cueva del Milodón", indicada como "cave" en el "Cave hill" (Fig. 3.1, 3.2). La presencia nativa en el mapa es nula.
Cabe señalar brevemente que el capitán Eberhard, de nacionalidad alemana, luego de trabajar en el archipiélago falklander/malvinero (para la compañía naviera "Kosmos") y establecerse en la estepa patagónica (fue propietario de la estancia "Chimen aike" en el territorio de Santa Cruz), lideró en el invierno de 1892 una exploración al

5 En la parte superior del mapa, se plantea la siguiente hipótesis: "Masa de agua con apariencia de lago, pero con mareas regulares por cuyo motivo de suponer ser cabeza de un estuario" en cuya masa de agua se indica que desemboca el río "Paine".

6 Se indica, con una línea segmentada azul, el derrotero completo por el seno de Última Esperanza de la escampavía de la Armada Nacional de Chile Toro; "Toro Agost-Sept. 1894".

7 Se incluyen los siguientes rótulos: "Undulanding camp covered with grass", "Thick brush Wood", "Low undulating country covered with thick impenetrable brushwood and intersected by many swamps", "Extensive glaciers \&snowfields", "Snowcapped mountains". Además, se agrega una viñeta indicando los elementos ambientales presentes en el mapa: "Explanation: Swamp, High Forest, Thick Brushwood, Pasture Land".

8 Se indica, con línea segmentada roja, la siguiente información caminera: "Camino de la S.U.E", track to morros Grandes", "Morros from Punta Dorotea, Dist: $36 \mathrm{ml}$, approx".

9 Se señala con una línea compuesta por equis negras "Probable límite con la Argentina" y una línea compuesta por equis rojas "Divortum aqua". 


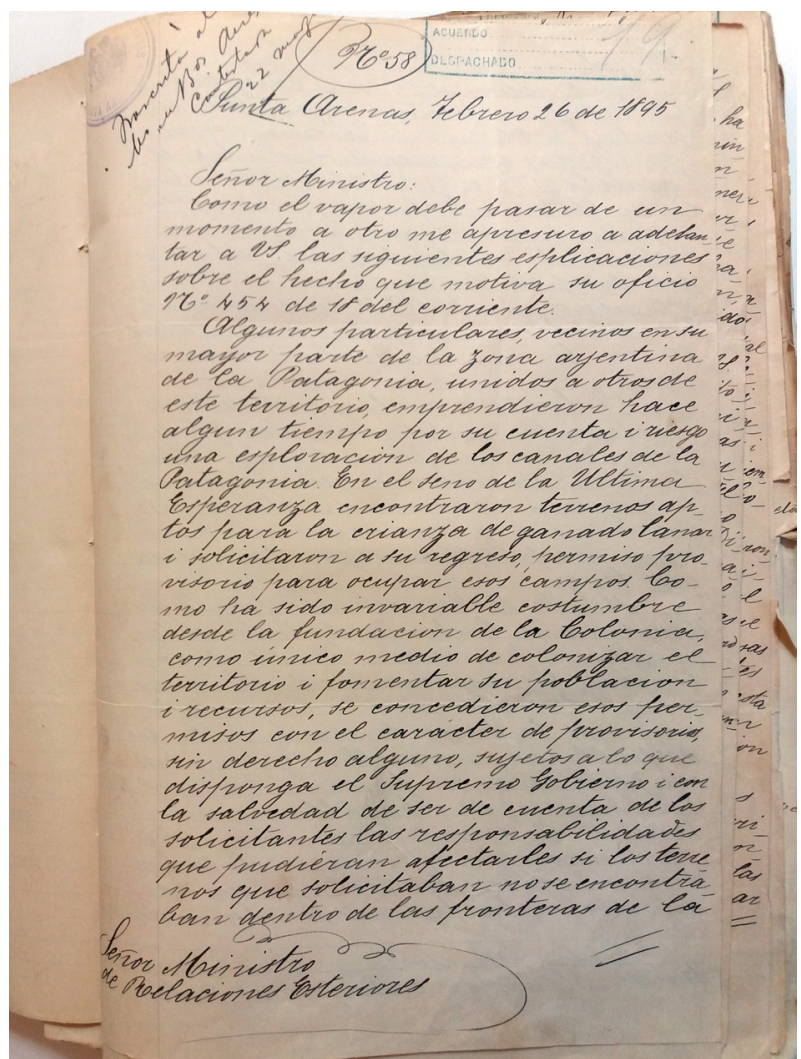

Fig. 2. Primera hoja del documento escrito por Manuel Señoret (fotografía del autor).

fiordo fuegopatagónico. La expedición se focalizó en el seno de Última Esperanza, comarca donde el alemán se estableció como estanciero a partir de $1894^{10}$, adquiriendo un conocimiento empírico y tangible sobre el territorio. Así es posible explicar su vínculo con el mapa en cuestión.

\section{II.}

El documento que se desclasifica es una respuesta que el gobernador de Magallanes Manuel Señoret (1892-1896) escribió al ministro de Relaciones Exteriores de Chile. Si bien la misiva del ministro se desconoce, se advierte que ésta tiene relación en conocer detalles respecto al estado de la colonización en la comarca de Última Esperanza y sobre ciertas acciones que Argentina pudiera estar realizando en un territorio que Chile asumía como propio tras el tratado de límites de 1881.

El escrito del gobernador de Magallanes tiene fecha de emisión el 26 de febrero de 1895.
En aquel entonces, la $5^{\text {ta }}$ Subcomisión de Límites estaba concluyendo los trabajos in situ de la demarcatoria fronteriza en la Tierra del Fuego. Luego, y comenzando en la Punta Dungeness, se procedería con la demarcación de la frontera en las estepas y cordilleras patagónicas. Sin embargo, como es sabido, en la comarca de Última Esperanza ya se visualizaban algunos descalces entre el saber geográfico metropolitano impreso en el tratado de límites de 1881 y las condiciones geográficas propias de la comarca. Saber y definir en qué punto el paralelo $52^{\circ}$ (en el cual se fijó la frontera) se intersectaba con la cordillera de los Andes era clave, pero por entonces, científicamente, no estaba claro. Sin embargo, y a pesar de esta confusa situación limítrofe, a partir de 1894 se fueron instalando en esta comarca los primeros estancieros. Esta colonización ganadera fue iniciada y liderada por Eberhard y otros ciudadanos, principalmente de nacionalidad alemana. Una primera descripción de este nuevo paisaje que comenzaba a delinearse

10 En octubre de 1893 Hermann Eberhard obtuvo un permiso provisorio de ocupación otorgado por la gobernación de Magallanes (Martinic, 2017). 
fue realizada por el agrimensor y funcionario del estado argentino Carlos Siewert ${ }^{11}$. Éste recorrió esta comarca en octubre de 1894 y a su paso aprovechó la caminería estanciera, que ya empezaba a trazar y configurar caminos, para desplazarse por el territorio (García-Oteiza, 2020; Siewert, 1896). De hecho, fragmentos de estos caminos fueron registrados en el mapa de Eberhard.

La respuesta de Señoret al ministro metropolitano da cuenta de los temores que existían respecto a un territorio soberanamente no garantizado para el estado de Chile. En primer lugar, Señoret realiza un bosquejo general sobre la situación colonizadora de la comarca de Última Esperanza. Ante la incertidumbre limítrofe del territorio, el gobernador explica que tomó ciertos resguardos y que, basándose en la divisoria de aguas, se preocupó de entregar lotes de terrenos por donde surcaban ríos que desembocan en el seno de Última Esperanza, es decir: en aguas del océano Pacífico. Señoret trata de orientar visual y geográficamente al ministro metropolitano a través de paralelos, meridianos, topónimos y puntos cardinales, pues "la orientación visual es importante sobre todo en los tiempos de conflicto" [op. cit. en De Diego, 2008, p. 51]. En este contexto, el mapa de Eberhard asume un rol preponderante, pues deviene en una transmisión geográfica elocuente. El mapa se transforma en un espacio desde el cual es posible "ver" otro espacio, uno desconocido y que es necesario conocer rápidamente, pues ni Señoret ni el ministro conocían personalmente la comarca en cuestión. Es más, el gobernador, en su Memoria anual, cerrada el 31 de julio de 1895, no efectúa mención alguna sobre la comarca de Última Esperanza ( $C f$. Señoret, 1895).

El mapa de Eberhard asume, al menos, un doble rol: el de instruir a la autoridad estatal sobre su aparente territorio y el de afinar cartográficamente los límites prediales de la concesión Eberhard. Al respecto, el gobernador del territorio planteaba: "Los

11 El agrimensor Carlos Siewert, funcionario del estado argentino, recorrió la comarca de Última Esperanza en octubre de 1894 y dio cuenta en su memoria de los primeros avances de acción ganadera (Siewert, 1896). De hecho, el mismo Siewert daba por argentina esta comarca, así lo expresó y ratificó también en su mapa publicado en 1897. permisos provisorios de ocupación en la Patagonia, no habiendo un plano de hijuelaciones, se han concedido necesariamente, siguiendo las mismas indicaciones del solicitante, quien ubica el lote de una manera caprichosa, según sus conveniencias" [Señoret, 1895, p. 14]. El plano de hijuelación de la comarca de Última Esperanza sería producido una década más tarde ${ }^{12}$. En este contexto, cabe preguntarse ¿qué quiere y qué no quiere mostrar el mapa de Eberhard?, tomando en cuenta que tanto el encuadre como la escala empleada en el dibujo son dispositivos visuales.

III.

Como se ha comentado, el mapa contiene una cantidad importante de denominaciones para los accidentes geográficos (montes, sierras, lagunas, bahías, fiordos, lagos, ríos, islas). Algunos de estos topónimos perduraron, otros fueron reemplazados. Sin embargo, diferentes accidentes -a pesar de tener una denominación en el mapa de Eberhard- con el tiempo quedaron sin nombre (de ser conocidos pasaron a ser des-conocidos). Tal es el caso de la laguna P. Meyer [Mayer ${ }^{13}$, cuerpo de agua que por décadas sirvió como elemento caminero, pues era un referente y paso obligado entre la comarca de Última Esperanza y Punta Arenas. De hecho, en el mapa de Eberhard el camino bordea la orilla sur de esta laguna (Fig. 3.2). Otro aspecto caminero interesante a mencionar es el rótulo "Camino de la S.U.E". Estas iniciales son el acrónimo de la "Sociedad Anónima de la Última Esperanza" conformada por Rodolfo Stubenrauch, Claudio Glimann, Augusto Karck, Jerman Karck y Carlos Heede. Esta entidad obtuvo el 12 de marzo de 1894 la concesión provisoria de 50.000 hectáreas ubicadas al norte de la concesión de Eberhard, paraje individualizado como "Castle Hill" (o "Cerro Castillo"). Gracias a Siewert se sabe

12 En 1905 se publicaron dos planos con la hijuelación de los terrenos fiscales de Última Esperanza, uno firmado por Agustín Renjifo y otro por Agustín Torrealba.

13 En algunos mapas figuraría como "L. P." 1905. En adelante, en la producción cartográfica esta laguna aparece sin denominación alguna. Luego de la demarcatoria definitiva efectuada en 1903, esta laguna quedó en la sección argentina del territorio, próxima al actual paso fronterizo argentino "Laurita". 


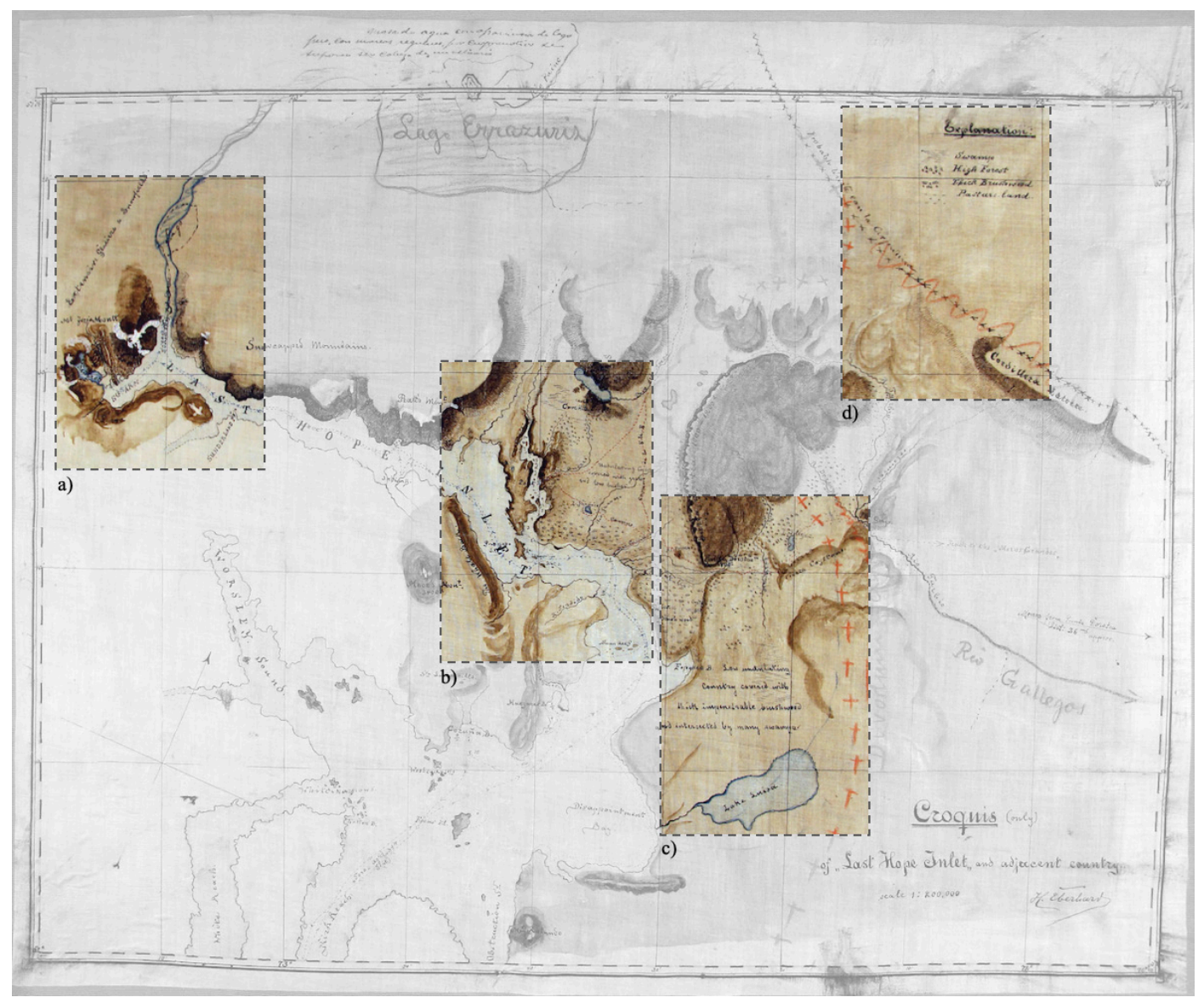

Fig. 3.1. Selección de áreas del mapa de Hermann Eberhard (intervención del autor).

que este camino ya estaba operativo, al menos, los últimos meses de 1894.

Llama fuertemente la atención el área que corresponde a la península Antonio Varas, la cual, a primera vista, parece un gran campo de hielo (nada ajeno al territorio). Ésta es representada casi en su totalidad en blanco, o bien por defecto con el color de la hoja. La península se distingue de las aguas del seno de Última Esperanza, las cuales son coloreadas sutilmente con color celeste. El dintorno de la península contrasta con el resto del territorio encuadrado en el mapa, el cual es trabajado con un buen nivel gráfico en el detalle orográfico (montes, cerros, montañas, mesetas, sierras) y lo restante simplemente coloreado de forma plana y homogénea (completando la hoja). Si bien este "blanco" alude automáticamente a la noción de lo "no conocido", lo "inexplorado", la "terra incognita", también puede ser entendido, epistemológicamente, como una forma de escritura. Un espacio que posibilita escribir una determinada forma de conocimiento geográfico o programa de conocimiento validado por el lenguaje científico dominante. Por ende, el "blanco" es además una forma de pensar lo conocido (Lois, 2018), una lógica occidental de escritura, donde lo nuevo expulsa lo antiguo (De Certeau, 2010). Otra conjetura respecto al "blanco" en el mapa se precisa con la siguiente interrogante: ¿puede esta gran superficie blanca ser el resultado de una precipitada entrega del mapa?, es decir, un trabajo no concluido, abandonado en plena faena de producción ${ }^{14}$. Por ahora, no es posible responder esta pregunta.

14 Esta posibilidad se presenta debido a que una cadena montañosa que colinda con la actual laguna "Sofía" lleva una S, la cual, siguiendo la lógica del mapa, podría ser la primera letra de la palabra "sierra", quedando incompleta u olvidada. 

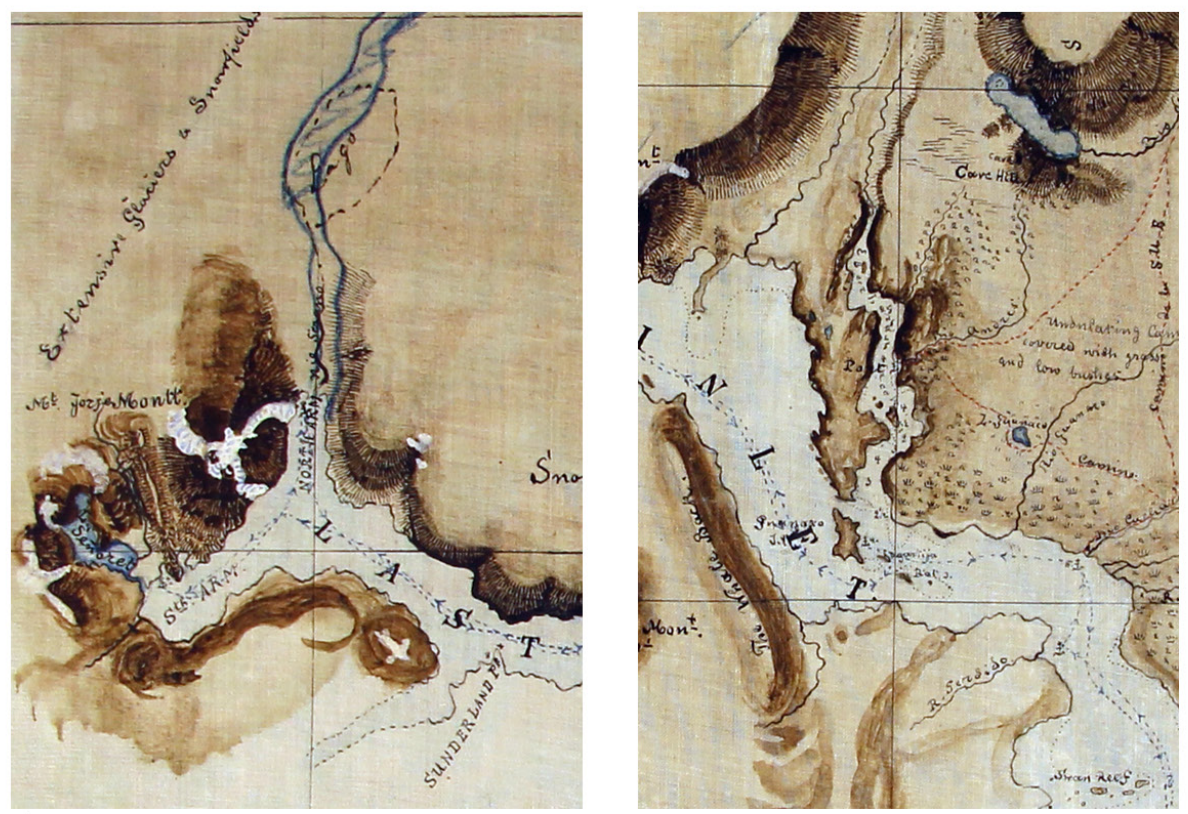

a)

b)
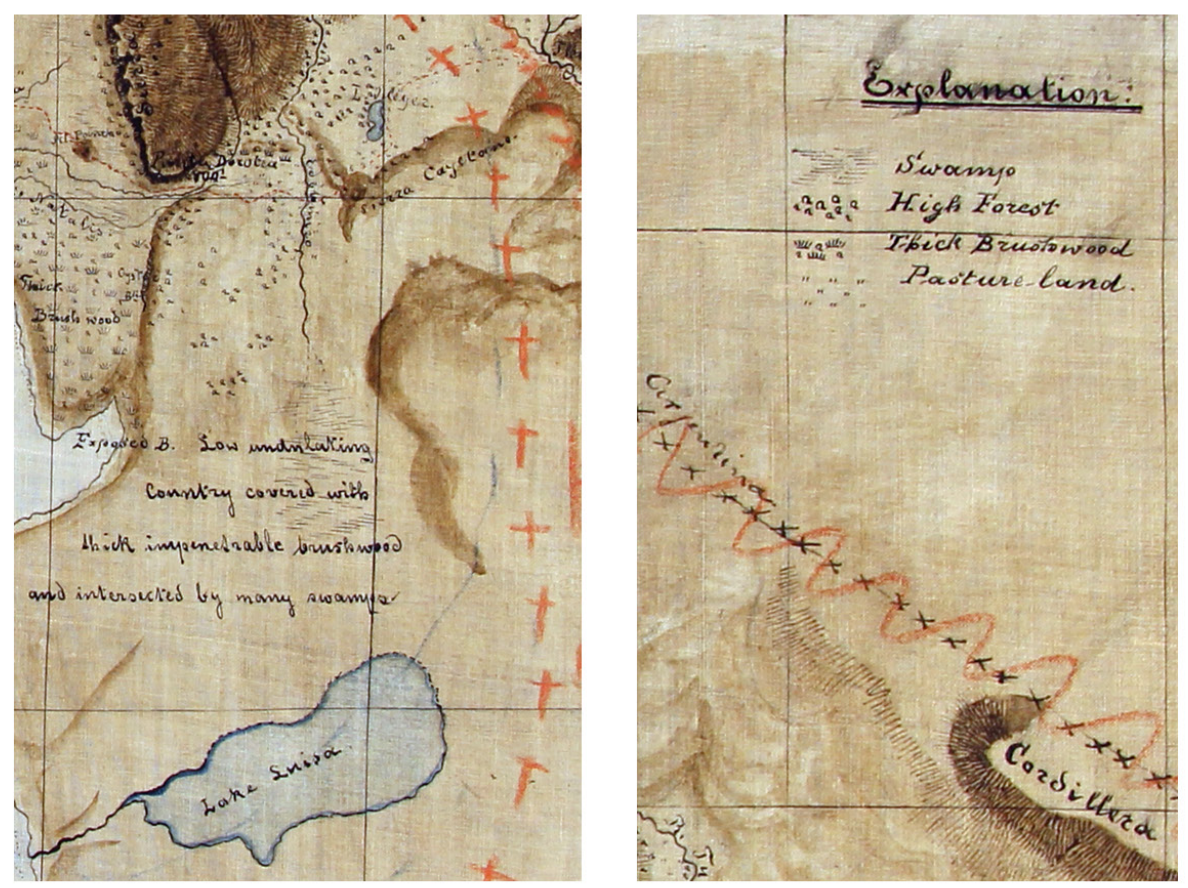

c)

d)

Fig. 3.2. Detalle del mapa de Hermann Eberhard (encuadres elaborados por el autor). 
Al cotejar el documento desclasificado y el mapa de Eberhard, se desprende que el contorno del cuerpo de agua identificado como "Lago Errazuriz" y su desembocadura en el "Last Hope Inlet", así como la línea compuesta por cruces de color rojo que señalan la Divortio acquarum", fueron intervenciones realizadas con posterioridad al envío del documento desde la gobernación de Magallanes. Es decir, fueron manipulaciones realizadas en la metrópoli santiaguina, deviniendo así el mapa en una especie de mesa de dibujo desde la cual se proyecta y diseña el territorio a distancia. En cuanto a su fecha de producción y contrario a lo deducido por Martinic, quien supuso que el mapa fue elaborado "bien avanzado el año 1895" [Martinic, 2017, p. 7], el documento confirma que este fue producido con anterioridad al 26 de febrero de 1895. Así, el mapa pudo haber sido confeccionado unos pocos meses o semanas antes de su llegada al escritorio del gobernador de Magallanes.

IV.

El mapa de Eberhard es una pieza documental que suscita diversas interrogantes en cuanto a su producción, contenido y circulación, cuyas indagatorias y el ensayo de sus posibles y parciales respuestas exceden con creces el objetivo de este trabajo. Sin embargo, es de interés dejarlas bosquejadas. Hay algunas operaciones gráficas que llaman la atención: ¿por qué la elección y utilización de tonos cafés para representar la superficie terrestre?; ¿por qué la masa arbórea, dominante en la comarca, no fue visualizada con su color convencional?; ¿no se disponía de otros colores?; ¿fue un gesto deliberado representar la comarca con un aspecto desértico, árido, sin vegetación "verde"?; ¿dónde Eberhard confeccionó el mapa?; ¿a quién estaba dirigido el mapa?; ¿lo produjo por iniciativa propia?; ¿fue por encargo?; ¿en qué momento y contexto llegó este mapa a manos del Gobernador de Magallanes? Si bien son muchas las preguntas en cuanto a lo que quiere y lo que no quiere decir-mostrar el mapa, no hay que descuidar también, como propone Matthew Edney, lo que se le hace decir al mapa (op. cit. en Lois, 2017).

El documento que se transcribe en esta entrega se encuentra en el Archivo Nacional de Chile, fondo; Ministerio de Relaciones Exteriores, volumen 691, año 1895. En cuanto a su transcripción, cabe indicar que se ha mantenido su formato original, es decir, tanto su ortografía, puntuación y frases subrayadas.

\section{DOCUMENTO}

Punta Arenas, Febrero 26 de 1895

Señor Ministro [de Relaciones Exteriores]:

Como el vapor debe pasar de un momento a otro me apresuro a adelantar a VS. las siguientes explicaciones sobre el hecho que motiva su oficio $N^{\circ} 454$ de 18 del corriente.

Algunos particulares, vecinos en su mayor parte de la zona argentina de la Patagonia, unidos a otros de este territorio, emprendieron hace algun tiempo por su cuenta i riesgo una esploracion de los canales de la Patagonia. En el seno de la Ultima Esperanza encontraron terrenos aptos para la crianza de ganado lanar i solicitaron a su regreso permiso provisorio para ocupar esos campos como ha sido invariable costumbre desde la fundacion de la Colonia [de Punta Arenas], como único medio de colonizar el territorio y fomentar su poblacion $i$ recursos, se concedieron esos permisos con el carácter de provisorios, sin derecho alguno, sujetos a lo que disponga el Supremo Gobierno i con la salvedad de ser de cuenta de los solicitantes las responsabilidades que pudieran afectarles si los terrenos que solicitaban no se encontraban dentro de las fronteras de la República.

Las concesiones son ocho o diez de quince mil hectáreas, cuyas copias textuales remitiré a VS. por el próscimo correo i están todas comprendidas entre el paralelo $51^{30}$ i el 51 al Norte del estuario de Ultima Esperanza en valles regados por ríos que desaguan directamente en las bahías i estuarios del Pacífico. No van mas al Oriente del meridiano de $72^{25}$, quedando al Este cordilleras nevadas cuyas vertientes son los ríos que acabo de mencionar.

A los $51^{\circ} 15^{\prime e}$ en longitud de $72^{\circ} 20^{\prime}$ se encuentra una masa de agua donde se hace sentir el flujo i reflujo lo que demuestra que 
esa masa tiene comunicación directa con el Oceano [Pacífico] y es cabeza de un estuario aun inesplorado, segun las noticias que tengo. Monte Hattes i Monte Payne quedan todavia bastante al Norte de las concesiones provisorias i no podrían tomarse los meridianos de esos cerros como referencia para estimar la posicion de la linea divisoria de las dos Repúblicas en aquella rejion, $i$ en este caso, como en general, tiene el gobernador de Magallanes que a tenerse el divortio acquarum para deducir la situacion de la frontera, mientras los trabajos de los peritos no la fijen definitivamente.

Entrando ahora al hecho material llevado a cabo por el Gobernador de Santa Cruz de espulsar a los alemanes, puedo asegurar a VS. que no me esplico como el hecho ha podido tener lugar por cuanto ninguno de ellos se ha establecido en esos terrenos pues, temerosos de tener dificultades con las autoridades arjentinas se proponian obtener de ellas igual concesion antes de hacer trabajo alguno de instalaciones, cosa que ignoro si han conseguido o no.

Para mayor inteligencia de VS. acompaño un croquis de los territorios de que se trata en esta comunicación. El valle cruzado con líneas de lápiz rojo está actualmente ocupado por la hacienda de ovejas del señor H. Eberhard con permiso provisorio de esta gobernacion. Directamente al Norte, hasta la masa de agua que figura cortando el marco del dibujo se estienden las otras concesiones. El señor Eberhard no ha sido molestado por las autoridades arjentinas i es el único establecido, desde mucho tiempo antes de las otras concesiones.

\section{BIBLIOGRAFÍA}

De Certeau, M. (2010). La escritura de la historia. Universidad Iberoamericana.

De Diego, E. (2008). Contra el mapa. Disturbios en la geografía colonial de occidente. Siruela.

Eberhard, K. (2018). El capitán Eberhard. Pionero de la Patagonia. Guanaco Libre.

Farocki, H. (2020). Desconfiar de las imágenes. Caja Negra.

García-Oteiza, S. (2020). Los caminos en Fuegopatagonia. Una encrucijada entre territorio y cartografía, 1870-1910. Tesis doctoral, Facultad de Arquitectura, Diseño y Estudios Urbanos, Pontificia Universidad Católica de Chile.

Lois, C. (2017). Matthew Edney. El reencuentro entre la historia de la cartografía y la geografía. Terra Brasilis (Nova Série), 9, 1-13.

Lois, C. (2018). Terra incognitae. Modos de pensar y mapear geografías desconocidas. Eudeba.

Martinic, M. (2017). Un novedoso mapa manuscrito del seno de Última Esperanza (1895). Magallania, 45(2), 5-10.

Rosenblitt, J., y Sanhueza, C. (Comp.) (2010). Cartografía Histórica de Chile 1778-1929. DIBAM

Señoret, M. (1895). Memoria que el Gobernador de Magallanes presenta al Ministro de Colonización en 1895. Imprenta Mejia.

Siewert, C. (1896). Un viaje a Patagonia (Región Austral del Territorio de Santa Cruz). Boletín del Instituto Geográfico Argentino, Tomo XVII, cuadernos 7, 8, 9, pp. 363-391.

Dios guie a VS.

Manuel Señoret 